\title{
ETHICS IN HUMAN EXPERIMENTATION
}

\author{
J. C. BEENHAKKER, B.Sc. (Physio.) (Rand) D.P.E. (Rand)*
}

Although there is no national policy regarding experiments done on human subjects, research institutions, which include Universities and training hospitals, usually have a review committee to screen all proposed research plans.

Certain factors are considered before permission is given, according to the Nuremburg Code and the Declaration of Helsinki.

1. All experiments must be done on animals first, wherever possible, before the use of human subjects.

2. Experiments may only be done by scientifically qualified persons and the importance of the advance of knowledge and any foreseeable benefits must be weighed against the inherent risk of any experimentation.

3. Any physical or mental suffering must be avoided and every protection against injury, disability and death must be taken.

4. Consent of the subject must be obtained and he must be informed regarding the nature, purpose and risk of the research. If the subject is a child, mentally retarded etc., informed consent must be obtained from the guardian. Special care must be taken in cases where the subject may be in a dependable position regarding the investigation, i.e. prisoner, student, subordinate etc., as such a subject may find it to his disadvantage to refuse permission.

5. The subject must feel free to withdraw his permission at any stage of the experiment and the investigator must discontinue the research if at any stage it appears to be harmful to the subject.
6. In clinical trials, the investigator is morally bound to give the patient the best possible treatment and one should not withhold any treatment if it may be of benefit to the patient. Acquisition of new medical knowledge should only be justified by its therapeutic value to that particular patient.

Legally an investigator can be prosecuted according to the common Law of Assault and, in civil cases, a signed consent does not absolve the investigator.

In research on animals, there are no international conventions governing experimentation although legally one is bound by the Animal Protection Act which states that there shall be no unnecessary suffering. Many institutions have an Animal Ethics Committee which ensures that animals receive every consideration for their bodily comfort, adequate and satisfactory housing adequate anaesthesia and analgesia and, where neces sary, effective euthanasia must be used. Animals must be treated with kindness and be properly fed and must receive meticulous post-operative care as a patient would in any hospital.

Many scientific journals insist that all investigations involving human and animal subjects, which are reported in their publications, must be conducted according to the above accepted moral and scientific principles and they will refuse papers which do not adhere to these principles.

\footnotetext{
* Senior Lecturer and Acting Head of Department, University of the Witwatersrand.
} 